\title{
NATURAL RESOURCE USE EFFICIENCY IN TECHNO-ECONOMIC SUSTAINABILITY ANALYSIS OF BIO-BASED PRODUCTS
}

\author{
Janusz Gołaszewski, Izabela Samson-Bręk, Barbara Kalisz, Krystyna Żuk-Gołaszewska \\ and Wioleta Radawiec \\ University of Warmia and Mazury; Center for Bioeconomy and Renewable Energies \\ Pl. Łódzki 3/202 10-727 Olsztyn, Poland
}

\begin{abstract}
This paper proposes a set of TEA-related, environmental sustainability indicators for an assessment of the resource use efficiency of bio-based products. The resource use includes consumption of material, energy, water and land area. Five indicators, i.e. biotic resource use efficiency, land use efficiency, biotic secondary resource use efficiency, abiotic resource use efficiency - water and energy, are associated with a direct input into TEA, while three, i.e. land use intensity, biodiversity and soil nutrient balance, are affected by the former. The exploitation of resources is associated with economic and social indicators connected with food and energy security, water scarcity and human welfare. The proposed set of indicators can be considered in the context of certification of bio-based products, although their applicability require specific case studies, determination of potential thresholds and aggregation in the context of environmental as well as economic and social sustainability assessment.
\end{abstract}

\section{KEYWORDS}

Sustainability Assessment, Bio-Based Products, Techno-Economic Analysis, Natural Resources

\section{INTRODUCTION}

Sustainable development of biomass-based products, such as food, feed, chemicals, materials and energy, requires efficient use of natural resources throughout a whole value chain. Resource use efficiency entails the rational use of natural biotic and abiotic resources, meaning that raw materials, energy, water and land should be used in a way which will reconcile production, energy and cost efficiency with the restitution of exploited resources. In order to attain the above goals, techno-economic activities should be considered on a life-cycle basis, including efficient and maximally productive resource use, extending the use of renewable resources and a cascade of conversions to other products at any stage of supply chain and end-of-life options. These measures should be accompanied by an estimation of internal life-cycle costs as well as costs attributed to environmental, economic and social externalities (STAR-ProBio (2019), Deliverable D8.1).

Sustainable bio-based products should be developed in accordance with the principles of circular economy, based on efficient use of primary resources and renewable energy, biodegradability and smart consumption followed by changes in diets and lifestyle. The origin of primary biomass resources in ecosystems and their production involve direct occupation of land, with subsequent indirect impacts on quality of water and soil and change in biodiversity. At consecutive stages of a value chain, other resources can become indispensable, including minerals and fossil energy. All the resource-use-based activities affect an ecosystem. A key challenge for bio-based production is to ensure that acquisition of primary biomass, processing, consumption and waste treatment at the end of the life of a product will not contribute to depletion of nutrients, biodiversity and habitat loss and deforestation, but rather they will facilitate reversion of land degradation and ecosystem restoration together with improvement of food, water and energy security. All these positive effects will finally contribute to the ecosystem's resilience. 
The first step in an evaluation of the sustainability of bio-based products is making a techno-economic analysis (TEA). In general, the TEA evaluates the technical performance and economic feasibility of bio-based product processing in a way which reflects uncertainties intrinsic to technological parameters and an economic risk. According to the methodological guidelines proposed by Lauer (2012), the TEA is a cost-benefit comparison that can be made with different methods. The methodology of the TEA applied by the National Advanced Biofuels Consortium entails a process modeling and an engineering design in connection with an economic evaluation in order to achieve a qualitative assessment of the impact that the technology and research breakthroughs have on the financial viability of a conversion strategy (NABC 2011). In the following stages of a TEA, R\&D results are implemented into a conceptual process design, followed by making a material and energy balance as well as capital and project cost estimates, and concluded by an economic analysis. The suggested approaches also include an environmental/sustainability analysis. The techno-economic sustainability analysis (TESA) of bio-based products developed by Briassoulis et al. (2020) divides the analysis into three integrated modules associated with: 1) resources, 2) conversion route, and 3) end-of-life (EoL) options.

This paper focuses on the first module, and is aimed at selecting among the indicators resulting from a TESA inventory that extends a techno-economic analysis into an assessment of the environmental sustainability aspects of bio-based products.

\section{METHODS}

Based on a literature review and the TEA methodology, a set of indicators was selected to assess the environmental sustainability of resource use in the production of bio-based products. Preliminary criteria for the selection of indicators were: having a reliable source, securing the availability of input data, quality of input data, and universality in an assessment of various bio-based resources and products. Other selection criteria were borrowed from Gołaszewski et al. (2019). They were: policy coherence for the development of bio-based products, ecosystem-related implications, a life-cycle perspective, the scientific background, rationale and relevance, and finally socio-economic awareness.

\section{RESULTS AND DISCUSSION}

Taking into account the dynamic development of biomass conversion technologies for the production of various types of chemicals and materials, a number of initiatives have been undertaken to elaborate a set of indicators for evaluating their compliance with the principles of sustainable development, particularly the sustainability of bioenergy and bio-based products (Samson-Bręk et al. 2019).

The Renewables Energy Directive (RED), passed in April 2009 (Directive 2009/28/EC), is an important regulation, the aim of which was to identify sustainability indicators. This directive established mandatory sustainability requirements for bioenergy carriers used as transport fuels and for liquid bioenergy carriers in general. In March 2010, the European Union Commission (EC) presented a report on the extension of the RED to all bioenergy carriers, and proposed that the RED criteria could be voluntarily adopted by the EU Member States to apply to solid and gaseous bioenergy carriers as well (COM(2010)11). In order to be sustainable, RED states that raw material for biofuel and bioenergy generation cannot be taken from primary forest, nature protection areas or highly biodiverse grassland. Land with high carbon stocks such as wetland or peatland can only be used under certain circumstances.

In 2011, FAO presented a tool for assessing, at the national level, the compliance of bioenergy systems with the principles of sustainable development, as a result of which sustainability indicators were elaborated under the Global Bioenergy Partnership (GBEP). The 24 indicators were developed in cooperation with many international governments and institutions, with a strong emphasis on providing results useful for analyzing policies at the national level and planning development based on the assessment of the existing bioenergy sector. 
Official databases, such as Eurostat, can be considered as sources of sustainable indicators. Eurostat provides an updated set of 28 agri-environmental indicators for the European Union countries, intended to monitor the integration of environmental concerns into the Common Agricultural Policy (CAP). The set of 35 indicators (EEA 2005) was defined in $\operatorname{COM}(2006) 508$ and $\operatorname{COM}(2001) 144$ at appropriate geographical levels and, as far as possible, on the basis of existing national data sources. All indicators originate from the DPSIR model (Forces - Pressures - State - Impacts - Responses) analysis. Interlinkages are shown for the major agri-environmental problems: water, land use and soil, climate change and air quality, biodiversity and landscape. The selected indicators are consistent with the specific objectives of the Agricultural Council's strategy on environmental integration and sustainable development contained in the Common Agricultural Policy (CAP). The European Commission Communication COM(2006)508 addresses outstanding issues and identifies 28 agri-environmental indicators to monitor the integration of environmental concerns into the CAP. These limitations do not invalidate the usefulness of the indicators for agri-environmental analysis. They suggest that further work is needed on these indicators to improve the methodological approaches, such as data collection methods, to develop new data sets where necessary, and to improve/validate existing modelling tools.

The concept of a value chain was originally developed by Porter (1985). The definition which was adopted here was given by Kaplinsky and Morris (2000), who define a value chain as "the full range of activities which are required to bring a product or service from conception, through the different phases of production (involving a combination of physical transformation and the input of various producer services), delivery to final customers, and final disposal after use." This paper slightly extends the meaning of a value chain by the inclusion of the notion of circularity of mass, energy and nutrients.

The scheme of the TEA in the context of a resource flow across an entire value chain of bio-based products that is covered by the proposed indicators is shown in Figure 1. The TEA input streams are associated with direct extraction of resources, including biotic (feedstock) and abiotic ones (water, soils, minerals), from ecosystems. At the same time, the stages of use/consumption and the EoL stage can provide significant contribution to sustainability by reduction of inputs through the use of secondary materials, recovered energy and restitution of an ecosystem.

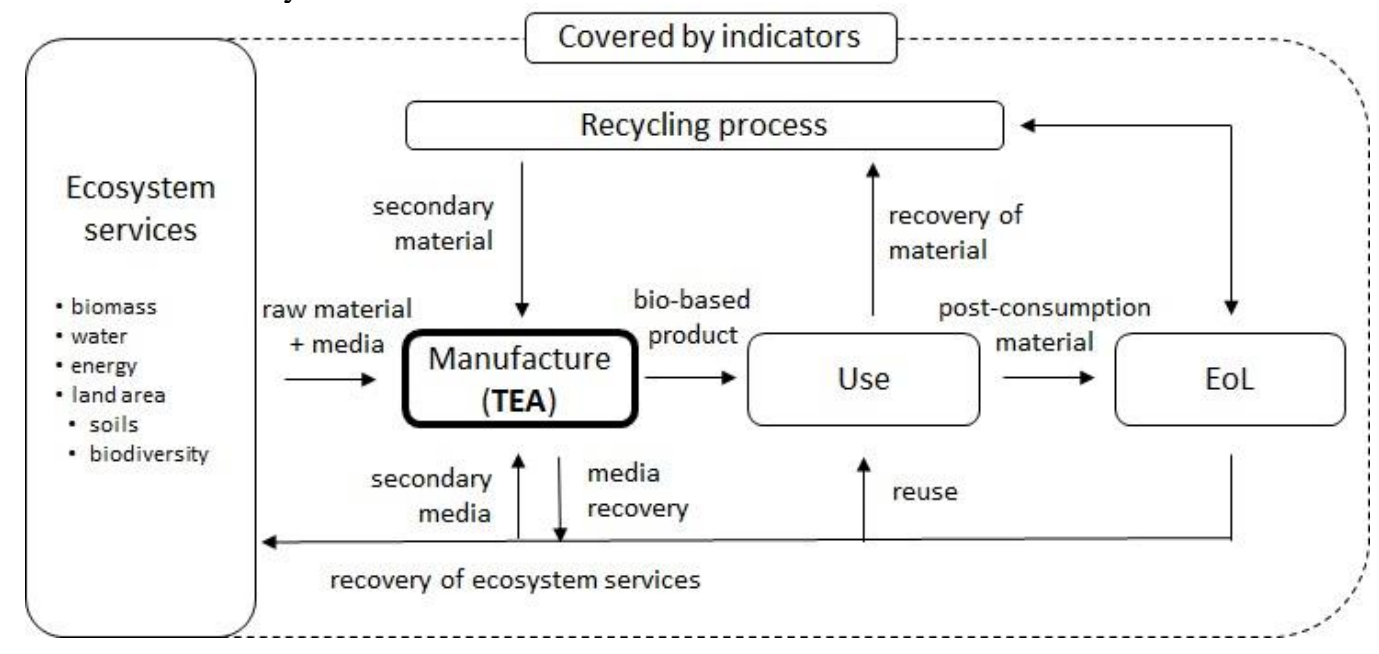

Figure 1. TEA in the framework of value chain for bio-based products

The 35 environmental indicators (STAR-ProBio (2019), Deliverable D2.2) were chosen as the reference set for the selection of eight TEA-related indicators of environmental sustainability associated with resource use efficiency (Table 1). The indicators include: biotic resource use efficiency, biodiversity, secondary resource use efficiency, soil nutrient balance, land use efficiency, land use intensity, and abiotic resource depletion of water and energy. A description of the indicators and methodology for their estimation can be found in the paper by Samson-Bręk et al. (2020).

The highest importance was given to indicators related to a TEA inventory associated with direct ecosystem inputs, including energy (100\%), water (100\%) and biotic resource use efficiency $(95 \%)$, followed by the impact on biodiversity (88\%). Next in order were measures associated with saving resources by secondary resource use (85\%), land use efficiency and intensity (77\%), and quality of soil (soil nutrient balance $77 \%$ ). 
Table 1. The set of selected TEA-related environmental sustainability indicators of resource use efficiency

\begin{tabular}{llc}
\hline Indicator & Provisional unit & Rating in \% \\
\hline Biotic resource use efficiency & Conversion ratio in $\mathrm{kg} / \mathrm{kg}$ & 95 \\
Land use efficiency & ha/t & 77 \\
Biotic secondary resource use efficiency & Conversion ratio in $\mathrm{kg} / \mathrm{kg}$ & 85 \\
Abiotic resource use efficiency: water & $\mathrm{m}^{3} / \mathrm{t}$ & 100 \\
Abiotic resource use efficiency: energy & $\mathrm{MJ} / \mathrm{t}$ & 100 \\
Land use intensity & normalized & 77 \\
Biodiversity (species richness loss) & normalized & 88 \\
Soil nutrient balance (N, P, SOC) & $\mathrm{kg} / \mathrm{t}$ & 77 \\
\hline
\end{tabular}

\section{CONCLUSION}

This paper proposes of a set of TEA related environmental sustainability indicators of resource use for bio-based products along a value chain. The indicators are based on the efficiency of resource use including material, energy, water and land. Five indicators, i.e. biotic resources use efficiency, land use efficiency, biotic secondary resource use efficiency, abiotic resource use efficiency - water and energy, are associated with a direct input into the TEA, while the other three, i.e. land use intensity, biodiversity and soil nutrient balance, are affected by the former. The exploitation of resources is associated with economic and social indicators connected with food and energy security, water scarcity and human welfare. The proposed set of indicators can be considered in the context of certification of bio-based products. Their applicability requires specific case studies, establishment of potential thresholds, and aggregation in the context of environmental as well as economic and social sustainability assessment.

\section{ACKNOWLEDGEMENT}

This paper is based on a study funded under the STAR-ProBio H2020 Grant Agreement 727740. Unless officially marked both Final and Public, this paper and its contents remain the property of the beneficiaries of the STAR-ProBio Consortium and may not be distributed or reproduced without the express written approval of the project's Coordinator.

\section{REFERENCES}

Briassoulis D. et al. 2020. Chapter 4. Techno-economic Sustainability Assessment: Methodological Approaches for Biobased Products. Green Chemistry Series No. 64. The Royal Society of Chemistry 2020.

$\operatorname{COM}(2001) 144$. Communication from the Commission to the Council and the European Parliament - Statistical Information needed for Indicators to monitor the Integration of Environmental concerns into the Common Agricultural Policy.

$\operatorname{COM}(2006) 508$. Communication from the Commission to the Council and the European Parliament - Development of agri-environmental indicators for monitoring the integration of environmental concerns into the common agricultural policy.

$\operatorname{COM}(2010) 11$. Report from the Commission to the Council and the European Parliament on sustainability requirements for the use of solid and gaseous biomass sources in electricity, heating and cooling.

Directive 2009/28/EC of the European Parliament and of the Council of 23 April 2009 on the promotion of the use of energy from renewable sources and amending and subsequently repealing Directives 2001/77/EC and 2003/30/EC.

EEA. 2005. Agriculture and environment in EU-15 - the IRENA indicator report, European Environment Agency, Copenhagen, 2005.

GBEP. www.globalbioenergy.org (accessed on 09.05.2019).

Gołaszewski J. et al. 2019. The ecosystem-based efficiency of resource use in assessment of the sustainability of bio-based products. 5th International Conference of Greening of Industry Network. Mexico City, Mexico. 
Kaplinsky R., Morris M. 2000. A handbook for value chain research. International Development Research Centre (Canada); Institute of Development Studies (Brighton, England)

Lauer M. 2008. Methodology guideline on techno-economic assessment (TEA) Generated in the Framework of ThermalNet. WP3B Economics.

NABC. 2011. Techno-Economic Analysis: Evaluating the Economic Viability and Potential of the NABC Process Strategies.

Porter M.E. 1985. Competitive Advantage: Creating and Sustaining Superior Performance. New York. Simon and Schuster.

Samson-Bręk I., Kalisz B., Żuk-Gołaszewska K., Radawiec W., Gołaszewski J. 2020. Sustainability aspects of resource use in biorefinery processing. (manuscript).

STAR-ProBio (2017), STAR-ProBio Deliverable D2.2, "Selection of environmental indicators and impact categories for the life cycle assessment of bio-based products.". Available from Internet: www.star-probio.eu.

STAR-ProBio (2019), STAR-ProBio Deliverable D8.1, "Recommendations concerning current sustainability standards associated with bio-based products and amendments to current standards of bio-based products". Available from Internet: www.star-probio.eu. 